\title{
CoVID-19 Pandemic as a Factor Revolutionizing the Industry of Higher Education
}

\author{
Yuriy Borysovych Melnyk ${ }^{1}$, Iryna Sergiivna Pypenko², Yuri Vsevolodovich \\ Maslov $^{3}$ \\ ${ }^{1}$ PhD, Professor, National Academy of the National Guard of Ukraine, Ukraine; \\ y.b.melnyk@gmail.com; https://orcid.org/oooo-ooo2-8527-4638 \\ ${ }^{2}$ PhD, Associate Professor, Simon Kuznets Kharkiv National University of Economics, \\ Ukraine; iryna.pypenko@hneu.net; https://orcid.org/oooo-ooo1-5083-540X \\ ${ }^{3}$ PhD, Associate Professor, Belarusian State Economic University, Belarus; maslove@tut.by; \\ https://orcid.org/oooo-0002-5715-6546
}

\begin{abstract}
Due to the CoVID-19 pandemic, the world has changed dramatically, and it will never be the same. Under the circumstances, a new type of specialist is in demand that possesses competency in information technologies and communication means, as well as in health culture. The problem of corporate health culture is becoming a serious issue in scientific discourse. The present paper deals with the results of the study aimed at the assessment of the higher education systems' preparedness for an emergency such as the CoVID-19 pandemic that affects the health of the participants in the educational process. The results were obtained through expert evaluations. The paper contains the analysis of the anonymous questionnaire answers obtained from the participants of the International Academic Conference "Psychological and Pedagogical Problems of Modern Specialist Formation" held online in June 2020 (Zoom Video Communications platform). The conference hosted over 200 researchers and practitioners in the field of education, psychology, and medicine representing 78 institutions from 20 countries located on five continents. The conference framework included a roundtable discussion accompanied by a questionnaire related to the organizational problems university education faced during the CoVID-19 pandemic. The analysis of the answers and expert opinions was conducted using the Pearson method $\chi^{2}$, which produced statistically relevant results. The analysis revealed marked differences in the attitudes of faculty (including gender differences) to the pandemic in terms of the organization of teaching at universities, the effect of social distancing measures on health (both physical and mental), and the value systems.
\end{abstract}

Keywords: University, Education, Culture, Health, CoVID-19

\section{Introduction}

The CoVID-19 pandemic is a global calamity of unprecedented proportions. The forest-fire speed of the spreading of the disease has already been highlighted numerous times. The pandemic left very little time, if any at all, for strategic planning or operational deliberation. The world had to react promptly and it did, with massive lockdowns across countries.

Such measures couldn't but cause multiple effects. The scale and magnitude of the ongoing transformations prove that it is not an exaggeration to posit that the pandemic politics will be the object of research for scholars across multiple disciplines for years and years to come (Williamson, Eynon, \& Potter, 2020).

(C) AesthetixMS 2020. This Open Access article is published under a Creative Commons Attribution Non-Commercial 4.0 International License (http://creativecommons.org/licenses/by-nc/4.0/), which permits non-commercial re-use, distribution, and reproduction in any medium, provided the original work is properly cited. For citation use the DOI. For commercial re-use, please contact editor@rupkatha.com. 
The present paper deals with the effects of the global pandemic on educational systems that found themselves at the forefront of the 'crisis operation'. Most authors emphasize that the common trend in education systems around the world has been to respond to the crisis with "emergency eLearning protocols" (Murphy, 2020).

No doubt, at the start of the pandemic the attention was primarily focused on "emergency remote teaching", not learning (Hodges, Moore, Lockee, Trust, \& Bond 2020). Under the circumstances, the objective was (and still is, unfortunately, in many countries) not to re-create a fully-fledged educational system but rather to provide temporary access to instruction and instructional support. This is what made emergency remote teaching (ERT) qualitatively different from the more familiar notion of "online learning" or "eLearning".

Under the circumstances, the present authors aim at monitoring the newly-forming attitudes of educators on a large scale, specifically in terms of their preparedness for the pandemic-affected educational practices.

\section{Material and Methods}

To evaluate educational institutions' level of preparedness for emergencies like the CoVID-19 pandemic that affect the physical and mental health of both educators and students several methods were employed. Those included data gathering, research literature review, a questionnaire developed by the authors, as well as action research conducted through an online round table discussion and held during the $6^{\text {th }}$ International Academic Conference "Psychological and Pedagogical Problems of Modern Specialist Formation" (doi: 10.26697/PPPMSF-20).

The international group of respondents consisted of 216 participants at the above conference. The questionnaire was administered by email to the representatives of 78 higher educational institutions from 20 countries. All the participants agreed to provide anonymous responses. During the round table, a discussion based on the questions ensued. Overall, 235 reports were received, and 216 met the requirements of the survey: the respondent, an educator at a higher education institution, engaged in emergency remote teaching and managed to respond to all the questions. The questionnaire consisted of a Likert-type scale containing five questions, four of which could be answered using the assigned values: +2 - "very positive/very high"; +1 "positive/high"; o - "undecided/neutral"; -1 - "negative/low"; -2 - "very negative/very low"; question five is a semi-structured interview.

The first question allows assessing the level (from very high to very low) of preparedness of an educational institution for emergency remote teaching in conditions of the CoVID-19 pandemic. The second question allows assessing the individual level (from very high to very low) of preparedness of an educator for emergency remote teaching. The third question allows assessing the individual level of satisfaction with educational outcomes of the emergency remote teaching. The fourth question is aimed at self-assessment of the level of physical and mental health in conditions of social distancing procedures provoked by the pandemic. The fifth question, being an open-ended one, requires an extended verbal response and is supposed to be a reflective answer that allows receiving research-related information on respondents' value changes in conditions of the pandemic. Such information may be of interest not only for the researchers but for the respondents as well. The research protocol is approved by the institutional research ethics committee, and the procedure complies with the ethical standards of research involving human subjects (the 1964 Helsinki Declaration and its subsequent amendments). 


\section{Results}

The overall results of the interviewing based on questions 1-4 are reflected in Table 1. Question 5 was open-ended and was not studied statistically as the respondents provided extended answers.

Table 1: Overall results of the survey.

\begin{tabular}{|c|c|c|c|c|c|c|c|c|c|c|c|c|}
\hline \multirow{3}{*}{ Question } & \multicolumn{10}{|c|}{ Number of respondents' answers according to the scale (n) } & & \\
\hline & \multicolumn{2}{|c|}{$\begin{array}{c}\text { Very } \\
\text { positive }\end{array}$} & \multicolumn{2}{|c|}{ Positive } & \multicolumn{2}{|c|}{ Negative } & \multicolumn{2}{|c|}{$\begin{array}{c}\text { Very } \\
\text { negative }\end{array}$} & \multicolumn{2}{|c|}{ Undecided } & \multicolumn{2}{|c|}{ Total } \\
\hline & $\mathrm{n}$ & $\%$ & $\mathrm{n}$ & $\%$ & $\mathrm{n}$ & $\%$ & $\mathrm{n}$ & $\%$ & $\mathrm{n}$ & $\%$ & $\mathrm{n}$ & $\%$ \\
\hline 1 & 72 & $33 \cdot 3$ & 64 & 29.6 & 45 & 20.8 & 13 & 6.1 & 22 & 10.2 & 216 & 100.0 \\
\hline 2 & 56 & 25.9 & 119 & 55.1 & 16 & $7 \cdot 4$ & 12 & 5.6 & 13 & 6.0 & 216 & 100.0 \\
\hline 3 & 48 & 22.2 & 100 & 46.3 & 40 & 18.5 & 16 & $7 \cdot 4$ & 12 & 5.6 & 216 & 100.0 \\
\hline 4 & 16 & 7.4 & 64 & 29.6 & 74 & $34 \cdot 3$ & 14 & 6.5 & 48 & 22.2 & 216 & 100.0 \\
\hline
\end{tabular}

The data presented in Table 1 show that answering the first question, the majority of respondents (62.9\%) evaluated highly the level of their respective educational institutions' preparedness for emergency remote teaching caused by CoVID-19 pandemic: $33.3 \%$ - very high and $29.6 \%$ - high. In contrast, $26.9 \%$ of respondents consider the above-mentioned level inadequate: $6.1 \%$ - very bad, and $20.8 \%$ - bad. $10.2 \%$ of respondents were unable to evaluate the above-mentioned level.

The answers to the second question show that $81.0 \%$ of respondents are prepared, as individuals, to conduct emergency remote teaching, which suggests a higher level of the individual level of readiness as compared with the institutional one (18.1\% higher). Specifically, $\mathbf{2 5 . 9} \%$ were very well prepared, and $55.1 \%$ were well prepared. In contrast, $\mathbf{1 3 . 0} \%$ rated their level of preparedness as inadequate: 5.6\% said it was "very low", and 7.4\% said it was "low". A group of respondents was unable to provide the answer to question $2(6.0 \%)$.

The answers to the third question showed that the majority of educators $(68.5 \%)$ were satisfied with the educational outcomes of emergency remote teaching practices $(\mathbf{2 2 . 2} \%$ obtained a very high level of satisfaction, $46.3 \%$ were just satisfied). A little more than a quarter of respondents $(25.9 \%)$ were not content with the educational outcomes during the pandemic. $18.5 \%$ of respondents rated the satisfaction level as "low", and $7.4 \%$ as "very low", with $5.6 \%$ of respondents being unable to evaluate the outcomes of emergency remote teaching.

The answers to the fourth question dealing with the effect of social distancing measures on physical and mental health demonstrated a different trend. The positive evaluation of the effect was given by $37.0 \%$ of respondents $(7.4 \%$ said it was "very positive", and $29.6 \%$ said it was "positive"). However, $40.8 \%$ of respondents evaluated the effect as "negative" (6.5\% said it was "very negative", $34.3 \%$ said it was "negative", and $22.2 \%$ were undecided).

We have also analyzed the respondents' answers from the gender perspective. We have observed the absence of marked differences in the answers to questions 1-3 between female and male respondents, as the levels of satisfaction are statistically quite similar; the existence of marked differences in the answers provided by female and male respondents to question 4. This leads us to posit the much greater negative effect on the physical and mental health of female educators produced by the emergency remote teaching situation.

The statistical differences were validated using the Pearson method $\chi^{2}$.

The study sample consisted of 216 responses obtained from 123 female and 93 male educators.

The differences were analyzed between the observed and the expected frequencies that 
follow the square distribution. The expected frequencies were determined based on group frequencies according to the null hypothesis. The statistical analysis was conducted using SPSS Statistics 26.

The statistical analysis reveals that the expected and observed frequencies have shown an insignificant difference in terms of responses to questions 1-3 ( $\chi^{2}$ values are not at a critical level). The null hypothesis stating the absence of differences has been confirmed.

Table 2 shows the data on the expected values' calculations based on the observed distribution frequencies in responses to question 4 .

Table 2: Data on expected values based on the observed distributions in the measure of the impact of social distancing procedures caused by the CoVID-19 pandemic on the respondents' selfassessment of physical and mental health.

\begin{tabular}{|c|c|c|c|c|c|c|c|c|c|c|c|}
\hline \multirow{3}{*}{ Parameter } & \multicolumn{10}{|c|}{$\begin{array}{c}\text { Observed (OV) and expected (EV) values grouped according to respondents' } \\
\text { answering scale }\end{array}$} & \multirow{3}{*}{ Total } \\
\hline & \multicolumn{2}{|c|}{ Very positive } & \multicolumn{2}{|c|}{ Positive } & \multicolumn{2}{|c|}{ Negative } & \multicolumn{2}{|c|}{ Very negative } & \multicolumn{2}{|c|}{ Undecided } & \\
\hline & $\mathrm{OV}$ & EV & $\mathrm{OV}$ & EV & $\mathrm{OV}$ & EV & $\mathrm{OV}$ & EV & $\mathrm{OV}$ & EV & \\
\hline Female & 5 & 9 & 33 & 36 & 53 & 42 & 9 & 8 & 23 & 27 & 123 \\
\hline Male & 11 & 7 & 31 & 28 & 21 & 32 & 5 & 6 & 25 & 21 & 93 \\
\hline Total & 16 & 16 & 64 & 64 & 74 & 74 & 14 & 14 & 48 & 48 & 216 \\
\hline $\begin{array}{l}\text { Ho-hypo- } \\
\text { thesis, \% }\end{array}$ & \multicolumn{2}{|c|}{7} & \multicolumn{2}{|c|}{30} & \multicolumn{2}{|c|}{34} & \multicolumn{2}{|c|}{7} & \multicolumn{2}{|c|}{22} & 100 \\
\hline
\end{tabular}

When dealing with the responses to question 4, marked differences have been observed $\left(\chi^{2}\right.$ values have achieved a critical level for a fixed number of degrees of freedom $\mathrm{df}=4$ ), so the null hypothesis has been rejected, which leads to the conclusion that statistically significant differences have been observed.

The critical value $\chi_{\text {cr }}^{2}$ for $\mathrm{df}=4: \chi_{\text {cr }}^{2}=13.277$ by $\mathrm{p}=0.01$.

The calculated value $\chi^{2}$ is bigger than the critical value (13.470>13.277), which confirms the fact that the differences in the compared aggregates of data are statistically significant $(\mathrm{df}=4$, $\left.\chi^{2}=13.470, \mathrm{p}<0.01\right)$.

Thus, the statistical analysis has proved that responses from female and male educators demonstrate no differences when answering the questions dealing with the level of institutional/individual preparedness for emergency remote teaching in conditions of the CoVID19 pandemic, as well as the degree of satisfaction with the outcomes of such teaching. The responses to the question dealing with the impact of social distancing procedures on physical and mental health have displayed a high measure of negativity, the attitude being more evident in the responses obtained from female educators and confirmed by the existence of statistically significant differences.

\section{Discussion}

The results obtained in the survey generally accord with the previous findings. Attempts have been made to analyze the lessons learned in the process of the remote teaching in the first months of the pandemic (Mahalakshmi \& Radha, 2020; Maslov, 2020). The authors agree that the emergency proved to be the wrong time for complex institutional planning, so the creation of a crisis-driven teaching/learning environment may have become "the biggest educational technology experiment in history" (Daniel, 2020). Speaking globally, humankind has been presented with an opportunity to view the world more holistically and realistically (Xafis, 
Schaefer, Labude, Zhu, \& Hsu, 2020). The prospects for using modern digital technologies in education were also described (Melnyk \& Pypenko, 2020).

Bracketing the existing digital divide, as well as the issues related to the public school systems, we'll focus on the crisis response by institutions of higher education. It varied from country to country. In most countries' higher education systems received direct recommendations on organizing ERT procedures.

In the digitally advanced countries, the transition occurred swiftly. For instance, top-25 U.S. universities discontinued face-to-face schooling at about the same time last March, and every university declared emergency eLearning policies (Murphy, 2020). In connection with that, the above author posits the idea that "the radical portability of eLearning" may be viewed as a new "emancipation" in higher education.

In developing countries ("digitally-developing", too), the response seems to be similarly prompt though there are many difficulties related to organizing effective eLearning practices. According to Adnan and Anwar (2020), a significant portion of Pakistani higher education learning/teaching is not conducted digitally, so the resources for emergency remote teaching are limited. In India, however, academics expect the COVID-19 pandemic "to be positive towards elearning" (Mahalakshmi \& Radha, 2020). It has also been noted that the lockdown-initiated transition to remote formats provides a great platform for the faculty members in terms of multiple opportunities for auto-didactic activities (Harsha \& Bai, 2020).

Educators had to adapt quickly to the new forms of actual teaching (Daniel, 2020; Morgan, 2020), as well as to the situation in the research area where some institutions have put research in fields such as the humanities and social sciences on hold (Nicola et al., 2020).

New concerns have emerged at once. Among many, some are connected with the pitfalls in the use of advanced technology: for instance, "zoom-bombing" etc. (Reich et al., 2020).

The crucial factor in organizing the educational process in conditions of the pandemic is the educators' psychological readiness for teaching under stress (Melnyk, Stadnik, \& Pypenko, 2020), as well as the policy of individual health protection and the development of student health culture (Melnyk, 2019).

The survey results have proved that the target group of educators from 20 countries was/is well prepared for the pandemic-driven ERT, which includes the flexibility of institutional support. The fact that about a quarter of the sample was not quite satisfied with the educational outcomes can be viewed not as an indicator of decline in the quality of teaching but rather as a direct effect of the teacher-specific neuroticism that works against overestimating the gains.

The actual educational "revolution" may be taking place in the system of professional values, which the answers to open-ended question 5 suggest. Many respondents focused on the more positive aspects of social distancing procedures that resulted in more time spent within the family circle. The majority, being professionals in the first place, preferred to focus on the impact of stimulating professional development and auto-didacticism. The survey participants reported "increased opportunities for research work", for "familiarizing with educational management platforms", for "wider contacts with the international educational community". Also mentioned was the emphasis on the lockdown as a means to conduct an "overall revision of the professionrelated values" in conditions that were brought about by health protection measures.

\section{Conclusions}

The results of the survey confirm the considerable impact of the CoVID-19 pandemic on conventional teaching across the world. ERT seemed to be the immediate alternative to face-toface teaching, and the majority of educators saw themselves prepared to conduct it. The present 
survey questioned the notion of the pandemic being a transformative, "revolution-laden" situation in higher education. The international sample group of educators responded in a way that makes the above assumption correct.

\section{References}

Adnan, M., \& Anwar, K. (2020). Online learning amid the COVID-19 pandemic: Students' perspectives. Journal of Pedagogical Sociology and Psychology, 2(1), 45-51. doi:10.33902/JPSP.2020261309

Daniel, S. J. (2020). Education and the COVID-19 pandemic. Prospects. doi:10.1007/s11125-020-09464-3

Harsha R., \& Bai, T (2020). COVID-19 lockdown: Challenges to higher education. Cape Comorin, 2(4), 26-28.

Hodges, Ch., Moore, S., Lockee, B., Trust, T., \& Bond, A. (2020, March 27). The difference between emergency remote teaching and online learning. Educause Review. Retrieved from https://er.educause.edu/articles/2020/3/the-difference-between-emergency-remote-teaching-andonline-learning

Mahalakshmi, K., \& Radha, R. (2020). COVID 19: A massive exposure towards web-based learning. Journal of Xidian University, 14(4), 2405-2411. doi:10.37896/jxu14.4/266

Maslov, Y. (2020). Lessons learned from emergency remote teaching during the COVID-19 pandemic. International Journal of Education and Science, 3(2), 30. doi:10.26697/ijes.2020.2.17

Melnyk, Yu. B., \& Pypenko, I. S. (2020). How will blockchain technology change education future?! International Journal of Science Annals, 3(1), 5-6. doi:10.26697/ijsa.2020.1.1

Melnyk, Yu. B., Stadnik, A. V., \& Pypenko, I. S. (2020). Resistance to post-traumatic stress reactions of vulnerable groups engaged in pandemic liquidation. International Journal of Science Annals, 3(1), 35-44. doi:10.26697/ijsa.2020.1.5

Melnyk, Yu. (2019). The influence of educational, physical cultural and healthy work on the formation of the health culture of master's students. Journal of Physical Education and Sport, 19(1), 219-226. doi:10.7752/jpes.2019.\$1033

Morgan, H. (2020). Best practices for implementing remote learning during a pandemic. The Clearing House: A Journal of Educational Strategies, Issues and Ideas, 93(3), 135-141. doi:10.1080/00098655.2020.1751480

Murphy, M. P. A. (2020). COVID-19 and emergency eLearning: Consequences of the securitization of higher education for post-pandemic pedagogy. Contemporary Security Policy, 41(3), 492-505, doi:10.1080/13523260.2020.1761749

Nicola, M., Alsafi, Z., Sohrabi, C., Kerwan, A., Al-Jabir, A., Iosifidis, Ch., ... Agha, R. (2020). The socioeconomic implications of the coronavirus pandemic (COVID-19): A review. International Journal of Surgery, 78, 185-193. doi:10.1016/j.ijsu.2020.04.018

Reich, J., Buttimer, C. J., Fang, A., Hillaire, G., Hirsch, K., Larke, L. R., ... Slama, R. (2020). Remote learning guidance from state education agencies during the COVID-19 pandemic: A first look. Retrieved from https://edarxiv.org/437e2/ doi:10.35542/osf.io/437e2

Williamson, B., Eynon, R., \& Potter, J. (2020). Pandemic politics, pedagogies and practices: Digital technologies and distance education during the coronavirus emergency. Learning, Media and Technology, 45(2), 107-114. doi:10.1080/17439884.2020.1761641

Xafis, V., Schaefer, G. O., Labude, M. K., Zhu, Y., \& Hsu, I. Y. (2020). The perfect moral storm: Diverse ethical considerations in the COVID-19 pandemic. Asian Bioethics Review, 12(2), 65-83. doi:10.1007/s41649-020-00125-3 